\title{
Awareness of Basic Life Support (BLS) Among Intern Doctors:-A Questionnaire Study
}

\author{
Dr. Ritesh Gajjar ${ }^{1}$, Dr. P.B.Gupta ${ }^{2}$ \\ ${ }^{I}$ Resident Doctor, Department Of Emergency Medicine, Government Medical College, Surat \\ ${ }^{2}$ Professor \& Head, Department Of Emergency Medicine, Government Medical College, Surat
}

\begin{abstract}
Intern doctors today are tomorrow's practitioners. One of the key skills that students should develop during their graduation training is to be prepared for cardiopulmonary resuscitation (CPR) anytime. With this cross-sectional study we are trying to explore the level of awareness about basic life support among the intern doctors of government medical college, Surat. A questionnaire with 20 questions regarding the knowledge and skills involved in BLS was used. After excluding the incomplete response forms the data was analyzed. The results were analyzed using an answer key prepared with the use of the basic and advanced cardiac life support manual. Out of 122 responders 72 were male and 50 were female. 23 intern doctors had BLS training in past. No one among them had complete knowledge of BLS. Only five out of $122(4 \%)$ had secured $80-89 \%$ marks, 14 out of $122(11 \%)$ had secured $70-79 \%$ marks, 15 of $122(12 \%)$ had secured $60-69 \%$ marks and 34 of 122 (28\%) had secured $50-59 \%$ marks. 44\% of them have secured less than 50\% marks. BLS awareness among intern doctors was below average. It can be improved by conducting well designed certified training programmes, so that the students will be well aware in these aspects right from the graduate level. Emergency medicine department should take the steps to organize such trainings.
\end{abstract}

Keywords: basic life support, cardio pulmonary resuscitation, awareness

\section{Introduction}

Cardiopulmonary resuscitation (CPR) is one of the most evolving areas of modern medicine which comprises a series of lifesaving actions that improve the survival rates following cardiac arrest [1]. Survival after cardiopulmonary arrest is usually low and depends on early intervention, quality of cardiopulmonary resuscitation (CPR) and early defibrillation [2-5]. Studies have shown that immediate CPR after collapse due to ventricular fibrillation doubles or even triples the chances of survival. In contrast survival chances decrease by $7-10 \%$ for every min, if CPR is delayed [6]. Individuals in the community at least the health care professionals should know how to perform BLS as they encounter such situation very often[7]. In the united states, BLS training has been recommended for all health care professionals since 1966[8], especially for those who are involved in resuscitation[9]. Intern doctors today are tomorrow's future practitioners. One of the key skills that every intern doctor should develop during their graduation training is to be prepared for emergency life saving situations like cardiopulmonary resuscitation (CPR) anytime, anywhere. As a preliminary step, with this study we have tried to explore the level of awareness about BLS among intern doctors in government medical college, surat. We hope that our study will help to guide future planning of BLS program in this hospital.

\section{Methods}

This was a questionnaire based study conducted in the government medical college, Surat, Gujarat after obtaining approval from the institutional ethics committee. It was conducted during the month of November 2016 - January 2017. Intern doctors of government medical college, Surat were included in the study. Those who were on leave, unwilling to participate in and incomplete questionnaires were excluded from the study. A questionnaire with 20 questions regarding the knowledge and skills involved in BLS was used to assess the levels of awareness to BLS and its practical knowledge among intern doctors. The aspects on which they were interrogated were about the abbreviation of BLS, CPR, CAB, AED, sequential steps in BLS algorithm, high quality CPR technique, assessment and resuscitation techniques with regard to airway, breathing, circulation in unresponsive victims of different age groups, and about choking. Information about attending any BLS course in past was also collected. The questions have been reviewed and validated by certified trained professionals who are currently involved in many BLS and ACLS (advanced cardiovascular life support) training programmes. The results were analysed using an answer key prepared with the use of the basic and advanced cardiac life support manual. The answered questions were rewarded as follows: +01 point for each question answered correctly and +00 point for questions answered incorrectly. After excluding the incomplete response forms, data entry, scores, descriptive statistics and response analyses was done using spss 17. 


\section{Results}

Out of 150 questionnaires which were distributed to the participants, 130 returned with a response rate of $87 \%$. Among the 130 questionnaires, 8 were incomplete, so they were excluded from the study. The age of the participants $(n=122)$ were ranged from 22-26 years (average 22.7 years). Out of all the participants, seventytwo (59\%) were male and fifty (41\%) were female. Twenty-four (19\%) interns had BLS training in past. BLS and CPR abbreviation were correctly recognized by all participants. Fifteen percent of the responders failed to answer the full form of $\mathrm{CAB}$ as circulation, airway and breathing. Fifty percent of participants did not know that looking for safety as the first step in BLS. Sixty-four percent failed to insist on activating EMS immediately after confirming the unresponsiveness in an adult. Seventy-four percent did not know that CPR is not aimed to restart the heart. Thirty percent of the responders did not know the critical characteristics of high quality CPR. Twenty-seven per cent did not know that the right location of chest compression is the lower half of breast bone. Seventy-three percent correctly answered the location of pulse check in adult as carotid artery while only twenty-seven percent of responders correctly answered the location of pulse check in infants as brachial artery. Fifty percent did not know that pulse check should not last more than 10 seconds. Only thirtyone percent of the responders answered the rate of chest compression as 100-120/minute in CPR. Only eleven percent know that the depth of chest compression in an adult is 2 to 2.4 inches. Fifty-five percent of the responders had correctly answered that the compression ventilation ratio in an adult single rescuer CPR is 30:2. Only twenty-seven percent knew that the ratio of compression ventilation in a child and new born with 2 rescuer is 15:1. Forty-eight percent of the responders did not know that the abbreviation of AED was 'automated external defibrillator, and only twenty six percent of participants know the exact steps to operate aed. Seventy-seven per cent did not know that the first step in helping a suspected foreign body obstruction victim is to confirm the severity of obstruction by talking to him. Only twenty three percent knew about the role of the recovery position in a spontaneously breathing unresponsive victim.

\section{Discussion}

Immediate cardiopulmonary resuscitation (CPR) and early defibrillation, with an automated external defibrillator (AED), can more than double a victim's chance of survival. In fact, early defibrillation, along with $\mathrm{CPR}$, is the only way to restore the victim's heart rhythm to normal in a lot of cases of cardiac arrest. Death from sudden cardiac arrest is not inevitable. If more people knew CPR, more lives could be saved [10]. This study revealed that the participants had inadequate knowledge on BLS. No one had complete knowledge on BLS. Only five out of $122(4 \%)$ had secured $80-89 \%$ marks. Fourteen of $122(11 \%)$ had secured $70-79 \%$ marks. In this study, only two question were correctly answered by all of the participants, whereas 9 questions were correctly answered by $<50 \%$ of them. The participants with BLS training in past scored better as compared to those without BLS training. Average score of participants with BLS training in past $(n=23)$ is 14/20 while average scope of participants without past BLS training $(n=99)$ is 10 .

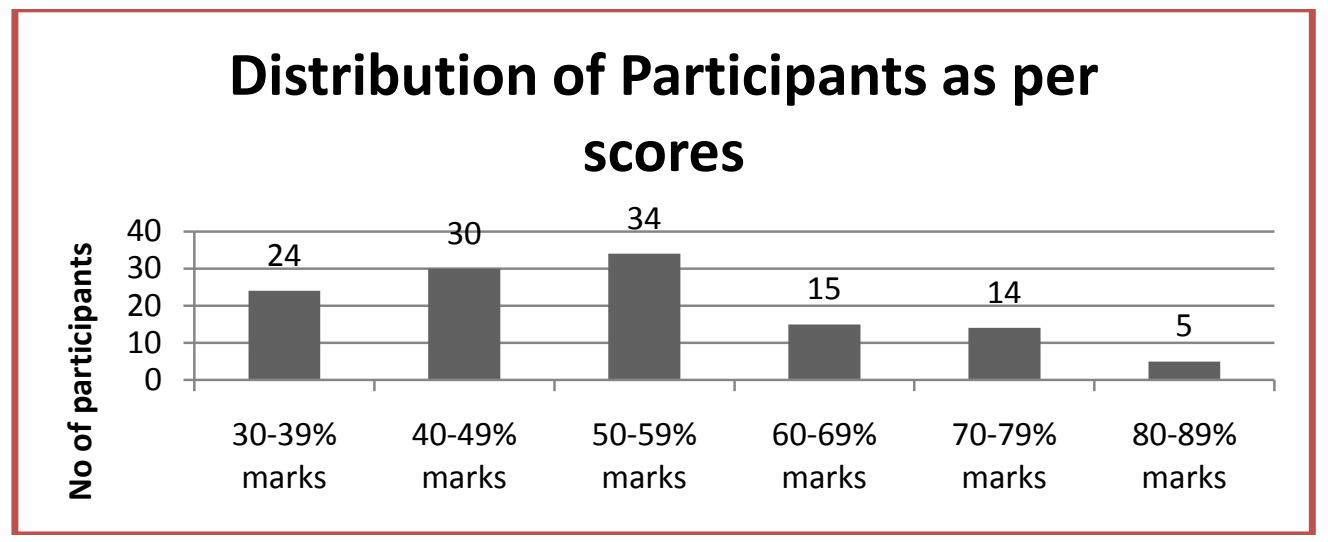

Retention of knowledge and skills during and after training in CPR is difficult and requires a more systematic training as well as methods that will ensure better retention of skills and information [11]. It is now essential to standardise training in basic life support and make it a mandatory component of all medical, nursing and paramedical school undergraduate curriculum [12]. The awareness on emergency medicine is increasing and the medical council of India has already approved emergency medicine as a separate specialty. Spreading awareness and teaching the basics of advanced life support to the medical and paramedical team as well as teaching BLS and first aid to the community will be the prime responsibility of this new emergency specialty. 


\section{Conclusion}

The ability to recognize and treat a respiratory or cardiac arrest is a basic medical skill that all heath care providers including intern doctors are generally expected to possess. From this study we can conclude that BLS awareness among intern doctors was below average. It can be improved by conducting well designed certified training programmes, so that the students will be well aware in these aspects right from the graduate level. Emergency medicine department should take the steps to organize such trainings. CPR is an important skill that everyone should learn. One need not be a medical professional to know or use CPR. It can be useful at any unknown time and place to save someone or to be a hero to a stranger. From this study, we would like to spread a strong message especially to all health care workers irrespective of their status should spare fair amount of time to get certified in CPR training and should enjoy executing the art of life saving.

\section{Acknowledgements}

We thankfully acknowledge the intern doctors of government medical college, Surat for their active participation in the study. Conflicts of interest: The authors declare that there is no conflict of interest.

\section{References}

[1]. Sasson C, Rogers Ma, Dahl J, Kellermann Al. Predictors Of Survival From Out-Of-Hospital Cardiac Arrest: A Systematic Review And Meta-Analysis. Circ Cardiovasc Qual Outcomes. 2010; 3: 63- 81.

[2]. Ritter G, Wolfe Ra, Goldstein S, Landis Jr, Vasu Cm, Acheson A, Et Al. The Effect Of By-Stander Cpr On Survival Of Out-OfHospital Cardiac Arrest Victims. Am Heart J 1985; 110: 932-937.

[3]. Wenzel V, Lehmkuhl P, Kubilis Ps, Idris Ah, Pichlmayr I. Poor Correlation Of Mouth-To-Mouth Ventilation Skills After Basic Life Support Training And 6 Months Later. Resuscitation 1997; 35: 129-134.

[4]. Wik L, Steen Pa, Bi Rcher Ng. Qual I Ty Of Bystander Cardiopulmonary Resuscitation Influences Outcome After Prehospital Cardiac Arrest. Resuscitation 1994; 28: 195-203.

[5]. Gwinnutt C, Columb M, Harris R. Outcome After Cardiac Arrest In Adults In Uk Hospitals: Effect Of The 1997 Guidelines. Resuscitation 2000; 47: 125-135.

[6]. Sarin H, Kappoor D. Adult Basic Life Support. Indian J Crit Care Med. 2006; 10(2): 95-104.

[7]. Cooper S, Johnston E, Priscott D. Immediate Lifesupport Training. Impact In A Primary Care Setting? Resuscitation 2007; 72: 92-99.

[8]. Cardiopulmonary Resuscitation: Statement By The Ad Hoc Committee On Cardiopulmonary Resuscitation Of The Division Of Medical Sciences, National Academy Of Sciences, National Research Council. Cardiopulmonary Resuscitation. Jama 1966; 198: 372-379.

[9]. Guidelines For The Provision Of Anaesthetic Services. Anesthetic Practice In Respect Of Resuscitation. Royal College Of Anesthetist; 1999.

[10]. Weisfeldt Ml, Et Al. Ventricular Tachyarrhythmias After Cardiac Arrest In Public Versus At Home. New England Journal Of Medicine, 2011; 364:313-321.

[11]. R. Hamilton, "Nurses' Knowledge And Skill Retention Following Cardiopulmonary Resuscitation Training: A Review Of The Literature," Journal Of Advanced Nursing, Vol. 51, No. 3, Pp. 288-297, 2005.

[12]. Steen Pa, Kramerjohansen J. Improving Cardiopulmonary Resuscitation Quality To Ensure Survival. Curr Opin Crit Care. 2008;14:299-304

Questionnaire:

\section{Appendix}

1. What Does "BLS" Stand For?

a) Best Life Support

b) Basic Life Support

c) Basic Lung Support

d) Basic Life Services

2. What Does CPR Stand For?

a) Cardiac Passive Resuscitation

b) Cardio Pulmonary Resuscitation

c) Chest Pulmonary Revival

d) Cardio Pulmonary Rescue

3. CAB in CPR Stands For?

a) Children, Adults, Babies

b) Cuts, Airs, Burns

c) Compressions, Airway, Breathing

d) None Of The Above

4. When You Find Someone Unresponsive In The Middle Of The Road, What Will Be Your First Response? (Note: You Are Alone There)

a) Open Airway

b) Start Chest Compression 
c) Look For Safety

d) Give Two Breathings

5. If You Confirm Somebody Is Not Responding To You Even After Shaking And Shouting At Him, What Will Be Your Immediate Action?

a) Start CPR

b) Activate Ems

c) Put Him In Recovery Position

d) Observe

6. CPR Aims To Restart The Heart.

a) Yes

b) No

c) May $\mathrm{Be}$

7. The Critical Characteristics Of High-Quality CPR Include Which Of The Following?

a) Minimize Interruptions

b) Push Hard And Fast

c) Starting Chest Compressions Within 10 Seconds

d) All Of The Above

8. What Is The Location For Chest Compression?

a) Left Side Of The Chest

b) Right Side Of The Chest

c) Mid Chest (Lower Half Of Breastbone)

d) Xiphisternum

9. What Is The Rate Of Compressions Per Minute As Specified In The 2015 American Heart Association Guidelines?

a) At Least 120

b) 80 To 100

c) At Least 100

d) 100 To 120

10. The Correct Depth Of Compression For An Adult Patient Is:

a) 1.5 To 2 Inches

b) At Least 2 Inches, Not More Than 2.4 Inches

c) 2 Inches

d) 2.5 To 3 Inches

11. How Long Should A Pulse Check Last?

a) As Long As It Takes To Find A Pulse

b) No More Than 2 Seconds

c) No More Than 5 Seconds

d) No More Than 10 Seconds

12. Where Should You Check For A Pulse In An Adult?

a) Carotid Artery

b) Brachial Artery

c) Femoral Artery

d) Radial Artery

13. Infants Responsiveness Is Checked By:

a) Shaking The Patient And Shouting

b) Patting The Patient's Feet Or Tapping

c) Splashing Cold Water On The Face

d) All Of The Above

14. An Infant's Pulse Should Be Checked By Which Artery?

a) Femoral

b) Carotid

c) Radial 
d) Brachial

15. In Adults, The Chest Compression And Ventilation Ratio For Single Rescuer CPR Is

a) $15: 2$

b) $5: 1$

c) $30: 2$

d) $15: 1$

16. In Children The Chest Compression And Ventilation Ratio For 2 Rescuer CPR Is

a) $15: 2$

b) $5: 1$

c) $30: 2$

d) $3: 1$

17. What Does Abbreviation AED Stands For?

a) Automated External Defibrillator

b) Automated Electrical Defibrillator

c) Advanced Electrical Defibrillator

d) Advanced External Defibrillator

18. The Proper Steps For Operating An AED Are:

a) Power On The AED, Attach Electrode Pads, Shock The Patient, Analyze The Rhythm

b) Attach Electrode Pads, Check Pulse, Shock Patient, Analyze Rhythm

c) Check Pulse, Attach Electrode Pads, Analyze Rhythm, Shock Patient

d) Power On The AED, Attach Electrode Pads, Analyze The Rhythm, Clear The Patient, Deliver Shock

19. You Are Witnessing An Adult Unresponsive Victim Who Has Been Submerged In Fresh Water And Just Removed From It. He Has Spontaneous Breathing, But He Is Unresponsive. What Is The First Step? (Need Of Recovery Position)

a) CPR For Two Minutes And Inform Ems

b) CPR For One Minute And Inform Ems

c) Compress The Abdomen To Remove The Water

d) Keep Him In Recovery Position

20. If You And Your Friend Are Having Food In A Canteen And Suddenly Your Friend Starts Expressing Symptoms Of Choking, What Will Be Your First Response? ( First Response Of Choking In Adult)

a) Give Abdominal Thrusts

b) Give Chest Compression

c) Confirm Foreign Body Aspiration By Talking To Him

d) Give Back Blows

Key Answers

1 (B) 2 (B) 3 (C) 4 (C) 5 (B) 6 (B) 7 (D) 8 (C) 9 (D) 10 (B) 11 (D) 12 (A) 13 (B) 14 (D) 15 (C) 16 (A) 17 (A) 18 (D)

19 (D) $20(\mathrm{C})$ 